\title{
Marinha do Brasil: \\ UMA TRAJETÓRIA DO ENFARDAMENTO
}

\author{
Brazilian Navy: a trajectory of uniform(ization)
}

\author{
Elizabeth Espindola Halpern ${ }^{1}$ \\ Ligia Costa Leite ${ }^{2}$
}

RESUMO

Realizou-se o exame sobre as fundações da Marinha do Brasil e de seus profissionais por meio de uma análise sócio-histórica, considerando que ambos, da forma como passaram a ser concebidos, têm uma trajetória histórica e uma origem e bases sociais. Acredita-se que eles sejam efeitos da racionalidade científica moderna e que foram produzidos no decorrer de um percurso atravessado por impactantes transformações no panorama do mundo contemporâneo ocidental. O enfardamento refere-se a um processo de assimilação dos valores e preceitos militares ao ponto de conformarem um "espírito" capaz de fazer do indivíduo um membro da organização militar a serviço da pátria. A trajetória do enfardamento se desenrolou, ao longo da história, através do processo de profissionalização do militar. Ademais, o enfardamento se atualiza diariamente no seio institucional por meio de diversas estratégias de formatação. Este artigo apresenta parte dos resultados da pesquisa que resultou na Tese de Doutorado do curso do Programa de Pós-Graduação do Instituto de Psiquiatria da Universidade Federal do Rio de Janeiro sobre militares que são pacientes alcoolistas de um ambulatório da Marinha do Brasil.

Palavras-chave: Militares. Recrutamento militar. Estado. Guerra. Racionalidade científica.

\section{ABSTRACT}

The examination of the foundations of Brazilian Navy and its professionals was conducted through a socio-historical analysis, considering that both have a historical trajectory and a source and social bases, based on the way they were conceived. It is believed that they are effects of the modern scientific rationality and that they were produced during a path traversed by striking changes in the panorama of

1 Doutoranda em Saúde Mental - Instituto de Psiquiatria da Universidade Federal do Rio de Janeiro (IPUB/UFRJ), Mestre em Saúde Coletiva pelo Instituto de Medicina Social da Universidade do Estado do Rio de Janeiro(IMS/UERJ), Especialista em Psicologia Médica Universidade do Estado do Rio de Janeiro (UERJ), Psicóloga e Capitão-de-Fragata da Marinha do Brasil.

2 Doutora em Comunicação pela Universidade Federal do Rio de Janeiro e Professora Colaboradora Instituto de Psiquiatria da Universidade Federal do Rio de Janeiro. 
contemporary Western world. The uniform(ization) refers to a process of assimilation of military values and precepts to conform a "spirit" in order to make the individual a member of the military organization and a homeland server. The trajectory of uniform(ization) was unfolded, throughout history, through the process of professionalization of the military. Besides, the uniform(ization) is daily updated within the institution through several strategies of framing. This article presents some results of the research that resulted in the Doctoral Thesis of the course of the Post-Graduate Institute of Psychiatry, Federal University of Rio de Janeiro on military who are alcoholic patients in an outpatient clinic of Brazilian Navy.

Keyword: Military personnel. Military recruitment. State. War. Scientific rationality.

\section{Introdução}

Para que se possa compreender como se deu a construção das instituições militares como a Marinha do Brasil (MB), bem como do enfardamento de seus integrantes, realizou-se um exame sobre suas fundações por meio de uma análise sócio-histórica, considerando que esta organização e seu profissional, da forma como passaram a ser concebidos, têm uma trajetória histórica e uma origem e bases sociais. Acredita-se que ambos sejam efeitos da racionalidade científica moderna, calcada na física clássica newtoniana, cujo paradigma mecânico tornou-se padrão de inteligibilidade para compreender o mundo, os indivíduos em suas relações. Em termos globais, esta racionalidade estaria presente ao longo de quatro séculos, desde o século XVI até o XIX (LUZ, 1988).

Com o surgimento da cosmovisão embasada no antropocentrismo humanista, em substituição ao teocentrismo medieval, ocorreram transformações significativas nas relações de poder, sociedade, política, economia e no próprio modo de ser dos indivíduos, afetando o saber e as práticas sociais, que se atualizaram em diversas instituições. Impregnadas por esta racionalidade determinadas organizações, tais como as militares, imbuíram-se de ordenar as relações sociais e de construir sujeitos segundo uma ordem racional moralizante, disciplinar, consonante com o capitalismo vigente. Apesar de o homem ter protagonizado a revolução nos costumes e ideias, ao mesmo tempo, ele foi reduzido a uma peça da imensa mecânica industrial, fabril e militar.

Ademais, por meio da análise do campo discursivo nesse recorte sócio-histórico, é possível compreender que, as noções e categorias presentes no próprio discurso que permeiam a vida em sociedade, também derivam desta racionalidade, tal como se observa no emprego de termos relacionados às engrenagens das máquinas, tais como "aparelho", "sistema", "circuito", entre outros. A influência desta concepção pode ser identificada, nos tempos da América portuguesa, nos princípios que regiam o sistema militar corporativo, sob a coordenação do Vice-rei: 
O comandante do corpo militar assumiria o papel de cabeça: os oficiais, sargentos, cabos e soldados, seriam os membros. A delimitação da função de cada militar da tropa paga e regular era pontuada em diversos manuais do século XVIII. O rompimento da ordem estabelecida era encarado como uma enfermidade. Em casos extremos era prevista a amputação do membro doente com vistas ao bom funcionamento do corpo militar. (COTTA, 2005: 5).

Imersa nesse paradigma, a MB foi sendo construída, assim como seus integrantes, atuando como membros articulados a serviço do Estado, embora prevaleça uma visão no senso comum de que esta instituição seria praticamente eterna e livre de contradições. Todavia, deseja-se demonstrar que a formação da instituição naval brasileira e de seus profissionais não ocorreu de modo linear; ao contrário, ela foi atravessada por "avanços" e "rupturas". Logo, essa análise não tem o compromisso com a sua evolução temporal, demarcada por eventos que se desenrolam em série, mas com os conflitos e paradoxos inerentes a esse processo que tendem a ser pasteurizados pela visão institucional. Afetadas por mecanismos de arrumação, ordenamento e purificação, em sintonia com a cosmologia ainda em vigor, as histórias navais são rotineiramente recontadas de modo a reforçar as tradições e os predicados dos militares, tornando-as isentas de tropeços ou de hiatos.

\section{A invenção do Estado Moderno, do exército nacional $e$ do soldado-cidadão}

O Estado nacional europeu foi uma das maiores invenções do mundo ocidental, constituído em um panorama onde se operavam mudanças impactantes nas relações sociais, econômicas, culturais, no mapa geopolítico e no campo do conhecimento. Em substituição aos Estados dinásticos dos séculos XI e XII, pequenos e pouco coesos, nos Estados-nação industriais europeus havia grandes formações, altamente integradas e interdependentes entre governo e governados (ELIAS, 2006: 153-165). Para garantir o alargamento de suas operações financeiras de modo a viabilizar a expansão comercial e a coleta de impostos, o rei/governante precisava dispor de uma força militar, tornando-se necessária uma transformação das práticas de combate. Em tempos de guerra, o governo central deveria ser capaz de recrutar para abastecer seus exércitos; em tempos de paz, precisaria ser capaz de criar administrações militares domésticas permanentes para garantir o ingresso de combatentes (ELIAS, 1987).

De modo a assegurar a existência e o crescimento do recém-criado Estado-nação, era fundamental que ele fosse capaz de guerrear para manter a coesão da pátria e se impor 
diante das ameaças externas (GILBERT, 2001). A concepção de um exército permanente tornou-se mais desejável, considerando que estava em pauta a consolidação de um poder armado com vistas ao fortalecimento do Estado-nação. Para tanto, deu-se inicio à construção do modelo de profissional militar que se ajustasse a essas necessidades, resultando na inovadora proposta de um soldado-cidadão, adestrado, submetido à hierarquia e disciplina militares, pronto para obedecer e comandar. Os indivíduos recrutados não podiam mais ser vagabundos e miseráveis arrebanhados a troco de dinheiro; passaram a ter valor: eram treinados e aprenderam a manejar o fuzil, precisando ser recuperados para retornar ao combate, sendo inadmissível perder homens como antes (FOUCAULT, 1975/2007;1979).

O exército moderno permanente organizou-se em torno da concessão do soldo (remuneração por serviços militares), permitindo a contratação dos sold-ados. Daí surgiu o inédito perfil de militar: o soldado-cidadão, recrutado em território doméstico, compatível com as necessidades econômicas capitalistas (BRASIL, 2007). Eles substituíram a contratação dos mercenários que compunham o antigo exército vassálico e que apresentavam muitas desvantagens: "não eram confiáveis quando mal pagos, recorriam ao saque e à pilhagem quando não eram vigiados de perto, causavam distúrbios disseminados na hora da desmobilização e custavam muito caro" (TILLY, 1996: 169).

A criação do binômio confiança-disciplina seria a chave para a inspiração heroica de um exército, acendendo o entusiasmo patriótico para lutar pela terra natal, minimizando a aversão ao recrutamento e a indiferença pelas causas das batalhas (GILBERT, 2001). O ethos guerreiro foi sendo inoculado nos indivíduos, mobilizando-os a provarem sua coragem em todas as oportunidades, a estarem sempre a postos, de armas em punho. Ele tornou-se um princípio de comportamento e sentimento, um código de honra dos guerreiros, de comando e de obediência que embasou a estrutura e os regulamentos militares (ELIAS, 1997). As instituições militares funcionariam como um microcosmo da nação e um espaço de exercício do dever cívico particularmente masculino, segundo a ideologia europeia da “nação em armas" (McCANN, 1977; BEATTIE, 2004).

Interessante notar que a guerra e a pátria foram duas construções históricas que serviram de ferramenta para assegurar a formação e o desenvolvimento dos Estados nacionais, sendo um pretexto para a montagem dos exércitos nacionais.

A guerra era vista por Maquiavel como a atividade mais essencial da vida política, atrelando o pensamento político ao militar (GILBERT, 2001). Mudanças na composição dos exércitos e na técnica transformaram o espírito da organização militar que, de defensiva, com a arte da fortificação medieval, passou a ser ofensiva, com a introdução da artilharia e de armas de fogo. As lutas passaram a ser travadas entre povos distintos, porquanto as diferenças e a animosidade entre os Estados foram se intensificando, fazendo com que a guerra fosse uma experiência cada vez mais total. 
Mais do que serem capazes de combater, os Estados nacionais europeus se desenvolveram com a aplicação da equação: guerra mais preparação para a guerra (TILLY, 1994). Em outras palavras, a guerra e os preparativos para o combate requeriam a organização de uma administração que fosse capaz de cobrar os tributos para a manutenção dos exércitos permanentes, extraindo diretamente da população os recursos para assegurar as ações beligerantes do Estado contra inimigos internos e externos. Somente um governo com uma estrutura política mais sofisticada conseguiria ser suficientemente competente para guerrear e para se preparar para ela:

Tentativas de adquirir homens, uniformes, armas, alojamentos e, acima de tudo, dinheiro para sustentar a atividade militar impeliu os funcionários do estado a criar estruturas administrativas que eram obrigados a fiscalizar e conservar. (TILLY, 1996: 186).

O exército moderno foi um reflexo do Estado considerando que o fortalecimento da unidade nacional dependeria da assimilação da ideia da obrigação militar, acatamento às leis e pagamento de impostos (PALMER, 2001). Portanto, os Estados fizeram as guerras, e as guerras fizeram os Estados, já que elas ajudaram os governos a construírem suas bases institucionais (TILLY, 1987).

No entanto, a própria propensão à guerra não é uma inclinação universal, mas fruto de um conjunto de condições que permitem o engajamento de um Estado em um conflito internacional, como resultado de uma aprendizagem: aprender a lutar. O Brasil e demais Estados latino-americanos não desenvolveram a capacidade ideológica ou organizacional para guerrear com objetivos políticos claros, envolvendo tempo e recursos. Suas sociedades não desenvolveram as engrenagens para as transformações logísticas e culturais exigidas pelo conflito internacional, faltando-lhes uma memória histórica exigida para a movimentação bélica, ou melhor, os repertórios culturais de guerra, até porque a maior parte dos conflitos políticos se deu no interior dos Estados, não entre eles. Na verdade, a guerra total requer uma mobilização que exige um grau de integração e de inclusão, uma organização política e administrativa capaz de modelar e direcionar a violência.

Na América Latina houve pouca militarização, organização e mobilização de recursos humanos e materiais para uso potencial com fins de combate. Não houve a busca por uma organização com o objetivo da guerra em mente, a guerra não foi contemplada em seu cardápio estratégico em razão da existência de uma mente profissional militar nãobeligerante. Consequentemente, os chamados patrióticos tendem a soar superficiais, assim como os apelos para os sacrifícios da própria vida em nome da pátria amada (CENTENO, 2002). 
A própria guerra do Paraguai serve de exemplo da incapacidade do Império brasileiro de gerir o conflito armado, excessivamente longo e travado em uma região muito distante do território provincial. De fato, essa experiência ocorreu desprovida do apoio das elites políticas e econômicas, desabastecida de recursos humanos para guarnecer as fileiras, o que exigiu medidas constantes para fazer o recrutamento de integrantes, enfim, ela se desenvolveu sem o endosso do povo que nutria imagem negativa do serviço militar. Ironicamente, as populações do interior reagiram como se o governo provincial fosse o inimigo.

\begin{abstract}
Nesse sentido, a guerra não foi capaz de gerar maior desenvolvimento das capacidades burocráticas do Estado central ou da província, na direção de uma especialização burocrática ou da criação de alianças entre o Estado e alguns setores dos grupos dominantes. Somente a muito custo os agentes do Império conseguiram os recursos necessários à mobilização. Ainda assim, esses recursos, tais como os libertos, não foram doados ou extraídos, mas comprados com o dinheiro público, obtido através de empréstimos, ou libertados pela própria Casa imperial (IZECKSOHN, 2004: 204).
\end{abstract}

Ela foi uma guerra limitada, ou seja, o governo imperial enfrentou dificuldades para infiltrar-se na sociedade, agindo com cautela para recrutar de modo a não melindrar as bases de apoio do regime monárquico, sendo obrigado a arcar com uma parte considerável de seus custos, enfim, agravando a situação financeira do país (CENTENO, 2002). Nessa concepção, esperava-se que a guerra promovesse o maior desenvolvimento da capacidade burocrática do Estado ou a criação de alianças com grupos dominantes (IZECKSOHN, 2004).

Porém, nem sempre isso ocorreu; a experiência dos países latino-americanos revela que não teria havido uma correlação positiva entre a guerra e a construção do Estado, como aconteceu nos países europeus. Para que a guerra contribuísse para o desenvolvimento institucional, o poder do Estado deveria estar calcado na sua capacidade de se relacionar com a sociedade de modo a ser apoiado por ela nas ocasiões em que ele precisasse agir, criando as bases de uma cidadania e lealdade ampliadas.

A possibilidade de resposta ao conflito armado seria viável caso houvesse a disponibilidade de recursos externos, a capacidade de organização do Estado e a existência de alianças com os atores sociais. A guerra, concebida como uma experiência que contribui para a edificação do Estado, seria mais do que um ato de violência militar, representaria uma forma organizada de violência, com objetivos políticos claros, envolvendo tempo e recursos e, por fim, exigindo um desenvolvimento organizacional substancial (CENTENO, 2002). 
Ademais, para que o Estado-nação pudesse se lançar em combate, ele deveria exercer controle sobre os indivíduos, fazendo-se necessário "controlar suas multiplicidades, utilizálas ao máximo e majorar o efeito útil de seu trabalho e sua atividade graças a um sistema de poder suscetível de controlá-los" (FOUCAULT, 1979: 105). Assim, o governo central procurou homogeneizar o povo impondo o emprego de uma só língua, religião, moeda assim como instrumentos legais, a materialização dos símbolos nacionais, construindo sistemas de comércio, transporte e comunicações. Acreditava-se que esta padronização pudesse fortalecer seus vínculos, facilitando o recrutamento e o pagamento dos impostos. "A própria guerra tornou-se uma experiência homogeneizadora, à medida que os soldados e marinheiros representavam toda a nação" (TILLY, 1996: 181).

Quanto à concepção de pátria como uma realidade nacional, ela seria uma representação de elite; inclusive, a percepção que se constrói das dimensões da pátria é variável e abstrata, geralmente se atendo à terra natal, não sendo um sentimento que se opera nacionalmente, em todos os seus espaços. "A pátria-nação é o resultado de uma construção que está por fazer" (COSTA, 1995: 155).

A inovadora concepção de patriotismo, "ideia-argamassa" conferiu solidez ao exército nacional e um elo transcendental entre a pátria e seus combatentes, como uma obrigação moral e um dever universal. Desse modo, esse conceito, historicamente construído, tinha como meta conclamar o povo a demonstrar amor incondicional a ela, em um apelo à sua emotividade, acionando a dimensão moral dos combatentes para oferecer, sem resistência, a própria vida em sacrifício. O patriotismo, produto de um contexto histórico, político, econômico e cultural, se transformou em uma forma de gerir a população, viabilizou uma conexão entre governantes e governados.

Embora as sociedades contemporâneas ainda estejam nos estágios iniciais da formação dos Estados e construção das nações, as ideologias nacionais cultivam um sentimento de orgulho quanto à própria identidade nacional, de modo a que a nação pareça ser um sistema social de grande valor, imutável e coeso, integrando segmentos regionais díspares e estratos sociais diferentes em torno de certos grupos centrais dominantes.

As ideologias nacionais geralmente as representam como formações muito antigas, quase eternas e imortais. (...) Em outras palavras: os Estados fizeram-se 'nacionais' em conexão com mudanças específicas na distribuição de poder entre governantes e governados, e entre os estratos sociais de suas sociedades - o que afetou a natureza da própria estratificação. (ELIAS, 2006: 159-160).

Na verdade, como foi apontado por um erudito francês Ernest Renan em 1882, a nação foi uma invenção nova naquele panorama (ELIAS, 2006). No que diz respeito ao que ocorreu 
em solo brasileiro, antes da chegada da Corte portuguesa ao Rio de Janeiro, o Brasil não existia politicamente, economicamente e nem culturalmente. A própria ideia de independência somente estava presente na visão dos políticos que lideraram o processo; mesmo após sua proclamação, o sentido de identidade brasileira era ausente: "A palavra pátria ainda tinha sentido ambíguo, mesmo depois da independência. Ela era frequentemente usada para denotar províncias e não o Brasil" (CARVALHO, 1995: 9).

Ainda, segundo José Murilo de Carvalho, apesar do processo de criação do Estado nacional ter se consolidado na forma de um país a partir de 1850 , não havia a perspectiva de ser uma nação investida de um sentimento de identidade. Para o povo brasileiro, a imagem de pátria demorou a fazer parte de seu horizonte mental uma vez que ele não participou da construção da imagem nacional, tendo apenas como elemento comum a religião e a língua. A nação brasileira ainda era uma ficção, permanecendo desse jeito nas primeiras décadas da República. Durante esse período, a concepção de pátria nem constava no sistema educativo, ou seja, não havia sequer uma preocupação em formar cidadãos munidos de conteúdos de moral e cívica.

Na realidade, a própria República foi proclamada sem participação popular ou movimento nacional, sem o "batismo popular". Até 1937, o povo ainda "não falava por si mesmo, não tinha voz própria, era ventríloquo, sua identidade e a identidade da nação eram outorgadas pelo regime" (CARVALHO, 1995: 9). O desabafo amargurado feito por Amaro, protagonista de o Bom Crioulo, ilustra essa situação:

Diabo de vida sem descanso! O tempo era pouco para um desgraçado cumprir todas as ordens. E não as cumprisse! Golilha com ele, quando não era logo metido em ferros... Ah! Vida, vida!... Escravo na fazenda, escravo a bordo, escravo em toda parte... E chamava-se a isso servir à pátria! (CAMINHA, 1895/2007: 47).

\section{A construção da Marinha do Brasil e o papel do recrutamento}

Interessante notar que, embora já existisse um poder naval brasileiro desde 1549, ele era voltado aos interesses da metrópole e da classe dominante colonial, sendo predominantemente lusitano. Com a chegada da Família Real ao Brasil, em 1808, aportou um Estado inteiro, inclusive quase toda a Marinha portuguesa; a partir daí, D. João criou a máquina administrativa naval (CARVALHO, 1928). Na verdade, tratava-se de um embrião de um aparelho de Estado cuja estrutura estava sendo sacodida desde as rebeliões provinciais, 
anteriores à independência, abalada por violentos choques entre os oficiais portugueses e brasileiros.

A discriminação contra os nativos despertava sentimentos de aversão da população contra os militares, que se confundia com sua repulsa aos portugueses. Isto levou D. Pedro I a expulsar os militares portugueses fiéis à metrópole, embora uma parcela deles tenha decidido permanecer no Brasil, aceitando a independência. Com efeito, movida pelos anseios dos nativistas, a Marinha brasileira foi deixando de ter uma identidade lusitana (SODRÉ, 1965).

O Brasil "independente" precisava montar uma estrutura política-administrativa que viabilizasse o funcionamento do novo Estado, adaptando as instituições que haviam sido importadas de Portugal à realidade social brasileira. Inicialmente, a Marinha brasileira teve como atribuição manter a unidade territorial, assegurando a independência política do país.

José Bonifácio foi quem lançou as bases da Marinha, em caráter imperioso e urgente face às múltiplas necessidades que se apresentavam. Destaca-se sua função de levar os exércitos da autoridade central para outras províncias do território nacional, cujo acesso somente poderia ser feito pela via marítima (SODRÉ, 1965). A implantação do Estado Nacional brasileiro não foi fruto de um processo pacífico e consensual.

$\mathrm{Na}$ realidade, a configuração do Exército e da Marinha nacionais acompanhou o processo de independência, cooperando de modo intenso para a delimitação do território nacional, de dimensões continentais. O Brasil imperial era atravessado por movimentos separatistas em diversas províncias, além de terem que se sobrepor aos interesses majoritários dos comerciantes portugueses (ARIAS NETO, 2006).

Desde a independência, a Marinha passou a desempenhar um papel importante no processo de controle interno da violência política e da política externa imperial, intentando promover a estabilidade na região da Bacia do Prata e contribuindo para a manutenção da soberania nacional (ARIAS NETO, 2001). Apesar do papel da força naval ter sido decisivo neste episódio, submetendo as províncias rebeladas ao governo central, evidenciando que a vitória alcançada foi viabilizada pela dominação do mar (MONTEIRO, 1981), a concepção da Marinha como uma instituição estruturada com um aparato administrativo-burocrático é uma invenção recente:

(...) o período de formação da Marinha Nacional se estendeu até o inicio do segundo reinado (1840), quando a política do regresso - que se iniciou em 1837 - tornou-se hegemônica através do Partido Conservador que capitaneou a centralização do Estado Imperial e promoveu grandes reformas no edifício político do Estado, inclusive nas Forças Armadas. A Marinha do Brasil foi definitivamente moldada 
e consolidada pelas mãos do consistório do Partido Conservador, constituído por Eusébio de Queiroz, Paulino José Soares de Souza e Joaquim José Rodrigues Torres (ARIAS NETO, 2006: 7).

Paulatinamente, ela começou a existir politicamente, tornando-se parte do projeto de edificação do Estado Nacional, colaborando para constituí-lo, conservá-lo, modificá-lo e instituí-lo, viabilizando o próprio aumento do poder naval. Na Constituição de 1824, artigo 150, uma diretiva vaga "da Força Militar" foi incluída no Capítulo VIII, pronunciando: "Uma Ordenança especial regulará a Organização do Exercito do Brazil, suas Promoções, Soldos e Disciplina, assim como da Força Naval". No artigo 145, ficou expresso que todos os brasileiros seriam obrigados a pegar em armas para sustentar a independência e a integridade do jovem Império, contra inimigos internos ou externos (BRASIL, 1824). As diretrizes contidas nesse capítulo da Constituição, composto por apenas seis artigos, se concentram em apenas três aspectos atrelados à obediência:

\begin{abstract}
Projeto e Constituição foram acordes em três pontos essenciais para a garantia da própria existência da força pública e da sua eficácia: em ser ela "essencialmente obediente" e não poder congregar-se como corpo deliberante; em ser-lhe jamais permissível reunir-se sem ordem da autoridade legítima; em assegurar as patentes dos oficiais, delas só privados por sentença passada em julgado no juízo competente (MONTEIRO, 1939 apud SODRÉ, 1965: 90).
\end{abstract}

Até aquele momento, inexistia o comprometimento do oficialato com a causa nacional, mormente porque não era possível confiar em uma esquadra em franco processo de formação, composta por militares de origem portuguesa. Ela sequer possuía uma estrutura capaz de fazer frente às esquadras das potências europeias. Poucos meses após a independência, a estrutura regular das tropas foi composta de forma rudimentar por mercenários que estranhavam clima, o serviço pesado e o extremo rigor dos regulamentos que previam severos castigos corporais. As fileiras também foram guarnecidas por estrangeiros atraídos pelas promessas de concessão de terras, por nobres arruinados, aldeões simplórios ou por indivíduos oriundos das sobras das tropas dissolvidas (COSTA, 1957; SODRÉ, 1965).

Muitos deles também foram escravos, homens livres e libertos de cor, buscando o ingresso voluntário na vida militar para superar uma vida de restrições ou para fugir da escravidão. Na verdade, a conscrição foi um instrumento de controle social fundamental para a consolidação do Estado; sendo que a sua capacidade ou incapacidade de recrutar espelharia a dimensão de sua força. $O$ recrutamento foi uma das estratégias de dominação que serviu à inclusão e exclusão de indivíduos, selecionando-os de acordo com os interesses políticos e econômicos (KRAAY, 2002). 
Ainda, por um tempo, a Marinha brasileira buscou apoio na contratação de mercenários. Com efeito, a composição dos integrantes da Armada Imperial era absolutamente heterogênea, inclusive, ela passou a integrar oficiais ingleses e norteamericanos para assumir os comandos navais, sendo o primeiro Almirante o Lord Cochrane que residia no Chile, encarregado de organizar a Marinha. "Ao ministro Luís da Cunha Moreira, titular da pasta, caberiam o esforço administrativo e medidas organizativas, mas a força militar teria feição inteiramente desprovida de caráter nacional" (SODRÉ, 1965: 92).

Diante da situação econômica gravíssima em solo brasileiro, a Marinha permaneceu mal aparelhada, possuindo apenas navios de madeira e a vela. Cedendo à pressão da Inglaterra e das tecnologias mais avançadas de construção dos navios mais sofisticados e complexos, fundados na metalurgia, a Marinha passou a adquirir as embarcações estrangeiras, passando a depender do exterior e, consequentemente, enfraquecendo a sua indústria naval. Mas essa dependência não se resumia à compra de material bélico, havia uma propensão à imitação dos modelos externos, incluindo: costumes, disciplina e fardamento, atraindo maior simpatia do povo.

A reprodução de certos costumes, valores, disciplina, fardamento, entre outros, ostentados pela Marinha brasileira, correspondia ao que era ansiado por segmentos influentes da população. A nação se via representada pela Marinha, cujos integrantes provinham das classes privilegiadas. Em contraste, o Exército despertava antipatia, sobretudo após a guerra do Paraguai, quando ocorreu o acesso de mulatos e negros ao oficialato era comum:

\footnotetext{
A Marinha permanecerá, como a diplomacia, um dos últimos redutos do preconceito ostensivo de raça e surgirá como ilha de brancos ou brancarões, num país de população predominantemente negra ou mestiçada. (...) uma vitrine bem cuidada, para dar a ideia do que não éramos, mas desejávamos ser, segundo os padrões da classe dominante (SODRÉ, 1965: 134).
}

A emergência das Forças Armadas brasileiras foi uma novidade histórica, tanto do ponto de vista da sua estrutura e características organizacionais, como no que se refere ao desempenho importante de suas funções no âmbito da política interna (ARIAS NETO, 2006).

Com efeito, a Marinha do Brasil (assim como outras instituições), emergiu como uma ferramenta do Estado que deveria intervir na vida das populações que precisavam ser organizadas obedecendo a uma lógica das novas relações sociais no universo do capitalismo, com a ciência a sua ideia dominante, um ingrediente central para a constituição e manutenção da ordem capitalista. Por meio dela, organizava-se racionalmente a produção econômica e o comportamento das classes e grupos sociais subordinados, ditando modelos 
de funcionamento em todos os âmbitos da atividade humana, o que possibilitou a própria reprodução desse sistema.

A MB organizou-se para auxiliar o Estado a instituir a ordem política centralista, ou melhor, em favor da unificação e centralização institucionais, facilitando a implantação de ações e decisões, evitando-se a dispersão. Dessa forma, tornou-se possível assegurar a implantação de políticas em diversos setores, garantindo intervenções eficazes de diferentes naturezas. A MB foi uma peça fundamental para assegurar a constituição e a integridade do complexo aparelho de Estado Nacional brasileiro, assim como para ajudar na formação social brasileira, até porque, no final do século XIX e inicio do século XX, buscava-se reorganizar o espaço físico dos centros urbanos brasileiros, procurando higienizar, disciplinar e organizar os grupos sociais (LUZ, 1982).

O recrutamento no Brasil ajuda a elucidar sobre como se deu a formação das Forças Armadas, desnudas das concepções românticas e heroicas que impregnaram a percepção popular. A historiografia memorialista, por exemplo, chamava de "voluntários da pátria" os indivíduos que foram recrutados para a guerra do Paraguai, quando, na prática, o voluntariado não correspondeu ao espírito do conscrito daquela época. Prevalecia a repulsa entre os civis, sobretudo porque era notória a existência dos castigos corporais e do rigor do regimento interno da Marinha. As péssimas condições dos serviços navais sempre dificultaram o recrutamento, incluindo o afastamento da família, a insalubridade a bordo, a rigidez das leis, os castigos corporais e as condições climáticas adversas. Segundo o Relatório do Ministro da Marinha, Francisco de Paulo da Silva Lobo:

O recrutamento continua a ser, por enquanto, uma necessidade de que não podemos prescindir, atenta a grande repugnância de nossa população parta a vida marítima. (...) Reconhece-se que é urgente estabelecer regras infalíveis para o recrutamento, de forma que não se dê azo à arbitrariedade, e que esse tributo como todos os outros, seja igualmente distribuído pelas diversas classes da sociedade. (RELATÓRIO, 1866: 14).

As formas como eram feitas as conscrições apontavam para a baixa capacidade dos agentes do Estado para reabastecer as fileiras no sul do Paraguai, fossem eles homens livres ou libertos.

De fato, o Estado falhou na tentativa de criar uma "cooperação compulsória”, essencial à formação de uma identidade coletiva que fosse estabelecida através do reconhecimento de laços comuns entre todos os cidadãos. Foi esta debilidade que levou o Estado a comprar 
libertos e aceitá-los, mesmo quando se encontravam fora das condições ideais. (IZECKSOHN, 2004: 182).

A constituição das Forças Armadas foi atravessada pelo debate controvertido a respeito do recrutamento militar, mormente no que tange o de escravos e de libertos, que se estendeu com maior vulto no decorrer do século XIX, período em que ocorreram rebeliões republicanas em todo o território brasileiro (KRAAY, 2006). Até 1837, os negros e mulatos só podiam pertencer às unidades milicianas, ao passo que o exército regular somente admitia brancos.

Aos poucos, com a modificação da cláusula constitucional de 1824 a respeito da segregação racial dos contingentes militares brasileiros, os escravos fugitivos foram atraídos para as fileiras, alterando a sua composição racial. Um sentimento de constrangimento pela proximidade entre escravos e soldados perdurou por um tempo, esperando-se uma demarcação clara entre essas categorias. Em linhas gerais, a conscrição militar era tida como um "tributo de sangue", segundo a terminologia aplicada pelos cidadãos do Império ao longo do século XIX, evocando a ocorrência de práticas sangrentas e arbitrárias (MENDES, 2004).

Sobretudo, o alistamento de escravos e de libertos durante a Guerra do Paraguai acabou ocorrendo para escapar da escravidão. Em geral, eles eram recrutados à força, alistados como substitutos ou buscavam refúgio no Exército (IZECKSOHN, 2004). Essa experiência foi definida como o "abrigo da farda", mesmo tendo chances de morrer em combate (KRAAY, 1996). No Brasil oitocentista, o significado da participação dos escravos e dos homens libertos que engajaram, forçada ou voluntariamente, nos vários corpos de tropas, demonstra que as bases das organizações militares brasileiras foram erigidas graças à herança de cativos e de negros em suas fileiras (CARVALHO, 2005). Muitos dos escravos-soldados que tiveram o reconhecimento de sua condição de liberdade permaneceram como soldados na guarnição do Exército brasileiro em Salvador. No entanto, suas motivações não contemplavam uma questão patriótica, o que justifica o número expressivo de deserções e de quarteladas (movimentos de indisciplina e de revolta nos quartéis). Havia significados distintos do recrutamento de negros livres e de cativos. Para muitos deles, tratava-se de uma alternativa de sobrevivência; para outros, era uma oportunidade de aprender a empunhar armas; havia os escravos que aproveitavam essa chance para se passarem por livres; outros, para saquear. De fato, desde o início do período colonial, os negros, pardos e índios foram incorporados às fileiras militares a serviço da dominação (KRAAY, 2002).

Em razão da necessidade imperativa de um maior contingente de militares para finalizar a guerra do Paraguai, o Imperador Pedro II decidiu ser mais assertivo quanto à libertação dos escravos para que pudessem ingressar nas fileiras e, adiante, integrar o Exército e a Marinha (IZECKSOHN, 2004). Contudo, a inclusão desse contingente na Marinha era mais restrita. Na verdade, ela só era uma atividade enobrecedora para quem 
fazia parte do quadro de oficiais, recebendo indivíduos oriundos da classe dominante, existindo uma grande distância entre a oficialidade e a tropa (SODRÉ, 1965).

Somente mais tarde, ao final do século XIX, é que monarquistas e republicanos passaram a acreditar na necessidade da implantação de reformas no Exército e na Marinha, sendo imperativo que se fizesse o aparelhamento militar e a revisão na formação dos seus quadros visando à sua profissionalização. Aos poucos, iniciou-se a substituição dos militares de nacionalidade portuguesa, dos oficiais de elite e dos mercenários; a carreira militar passou a exigir a instrução especializada de seu contingente, dando margem à valorização do talento (SCHULZ, 1994).

A Marinha brasileira encontrava-se em franca defasagem em relação às outras nações por não ter adquirido os avanços tecnológicos da época, como a propulsão a vapor, em substituição à navegação à vela. Para superar a sua decadência, era preciso implantar um programa de reestruturação naval, incluindo a organização marítima e a educação da oficialidade (ARIAS NETO, 2001). A constatação do despreparo militar despertou, entre políticos e estadistas brasileiros, o desejo por novo pensamento estratégico-naval e a necessidade de rever o papel da Marinha. Portanto, deixaram de prevalecer os critérios de afinidades do sistema aristocrático que garantiam a ocupação de jovens oficiais em altos cargos; a promoção passou a se fazer por antiguidade, respeitando os méritos pessoais na carreira, evitando a anterior estagnação em postos subalternos daqueles que não pertenciam à elite.

Adiante, o nacionalismo militarista, derivado do modelo prussiano do século XX, destacou a importância da família nuclear heterossexual como um alicerce necessário à estabilidade social e metáfora para a nação. "Implícita na metáfora da guerra estava a ideia de que um país derrotado se tornava uma nação de emasculados, incapazes de proteger a virtude coletiva" (BEATTIE, 2004: 274). No Brasil, visava-se a transmutar a imagem dos quartéis, espaço social tido como suspeito e lugar de desonra que abrigava os homens solteiros perigosos. Era preciso amalgamar a crença de uma vida militar associada ao dever varonil respeitável no imaginário da sociedade.

Com a República, foram traçados os rumos para o reaparelhamento naval de modo a incorporar as inovações tecnológicas na esfera da navegação. Ela significava o estabelecimento de profundas modificações políticas no plano das relações Estadosociedade, assim como nas relações com a economia e a ideologia, com destaque ao liberalismo, aos direitos individuais, à moralização dos costumes e das instituições. Cabia à Marinha organizar-se em torno de um novo papel, não mais em escala regional, mas prontificando-se para se posicionar em um cenário bélico internacional que se encontrava em guerra, integrando militares com um novo perfil. 
Alguns representantes intelectuais brasileiros, tais como Olavo Bilac e Caetano de Faria, consideravam "o serviço militar como o instrumento de fortalecimento do patriotismo, onde a caserna seria o filtro da 'índole negativa' do brasileiro, assinalando três pontos básicos para a existência do patriotismo: consciência, coesão e disciplina" (LUZ, 1982: 46).

Com efeito, a conscrição de 1916 impulsionada pela I Guerra Mundial, esforçava-se para atrair voluntários. Para tal, o Exército e a Marinha veicularam uma propaganda que tentava convencer o público de que o serviço militar era viril, que os quartéis eram um típico lar nacional e que os militares eram uma família vitoriosa. A cultura militar encorajava a hipermasculinidade, estimulando demonstrações públicas através de confrontos violentos e conquistas sexuais (BEATTIE, 2004).

A Marinha republicana se comprometeu a assegurar a soberania nacional e a manter a ordem interna, incorporando o conceito de defesa nacional, em compasso com o recente processo de nacionalização e de independência política brasileira. A criação de novos regulamentos, como o atual Estatuto dos Militares (BRASIL, 1980) ${ }^{3}$, representa um dos resultados dessas transformações e, sobretudo, a expressão de uma racionalidade em ação, superando o perfil discriminatório do antigo Estatuto dos Militares de 1946 (RODRIGUES, 2004).

Contudo, ainda por um bom tempo, prevaleceu a influência filosófica prussiana de Frederico II que duvidava da inteligência do soldado e que rejeitava programas educacionais. Acreditava-se que: "O soldado deve temer seus oficiais mais do que seus inimigos", um ponto de vista que embasou a redação dos códigos penais e disciplinares, sobretudo calcados na punição corporal (McBETH, 1977).

A despeito do processo de modernização pelo qual a Marinha viveu a partir do final do século XIX, seus regulamentos continuaram sob a influência do espírito draconiano. Até a Revolta da Chibata, eles permaneceram "anacrônicos, permitindo até mesmo que a oficialidade continuasse a dispor do direito de aplicar em seus subalternos punições arbitrárias e degradantes, que ficavam permanentemente registradas em suas cadernetas" (RODRIGUES, 2004: 59).

\section{A invenção do profissional militar naval: a trajetória do enfardamento}

3 BRASIL. Lei no 6.880, de 9 de dezembro de 1980. Dispõe sobre o Estatuto dos Militares. Rio de Janeiro, Serviço de Documentação da Marinha. Diário Oficial da União, Título I de 11 de dezembro, 1980. 
Apesar de terem existido navios e guerras desde a Antiguidade até o período medieval, essas marinhas não eram concebidas como as da atualidade. Havia o uso do mar com propósitos bélicos, porém, grandes limitações se impunham à navegação e aos seus objetivos, tais como o uso do remo como força propulsora das galeras; a reduzida capacidade de armazenamento de água, durando poucos dias; a pequena resistência estrutural das embarcações ao tempo, aguentando por cerca de seis a oito meses; pela restrita disponibilidade de pessoal para tripular os navios; e, pela extrema dependência do porto para reparos e abastecimento (BRASIL, 2007).

Com efeito, os predicados necessários para o indivíduo se tornar marujo exigiam robustez física para sobreviver às condições adversas da vida no mar. Acreditava-se que a única forma de manter a disciplina dessas "feras", compatíveis com um tipo "sub-humano", recrutados à força, seria pelo impiedoso uso da chibata (MARTINS, 2005: 79).

$\mathrm{Na}$ época das galeras, criava-se uma frota em menos de um ano, composta por alguns marinheiros (pescadores e mercadores) e muitos cidadãos, súditos e escravos, sem qualquer experiência no mar. Adiante, o navio a vela, denominado caravela, alterou a vida do navegador no mar. As longas viagens e a maior permanência nos oceanos tornaram-se possíveis, sem a dependência do porto:

\begin{abstract}
A centralidade que a vida de bordo passou a ter para a identidade dos oficiais e marinheiros vêm desta época, porque, até então, era normal que as marinhas fossem formadas para a guerra a partir de alguns navios de Estado, ou resultassem do processo de armamento de navios mercantes ou ainda da incorporação de corsários (privateers), fazendo com que, cessado o motivo que havia levado à formação da esquadra, esta fosse inteiramente desmobilizada. (BRASIL, 2007: 4-3)
\end{abstract}

Uma das formas de se divisar como a formação da profissão naval se estruturou pode ser feita por meio do embate travado entre duas lógicas na Inglaterra do século XVI: a oposição entre oficiais-marinheiros (das classes baixas e médias urbanas) e oficiaisgentlemen, (da classe alta e pequena nobreza) (ELIAS, 2001). Os primeiros, representados por Francis Drake, eram considerados "homens do mar" com os atributos náuticos artesanais, adquiridos desde crianças, desenvolvidos pela prática rústica exigida nas embarcações movidas à vela. Os segundos, ilustrados pelo seu rival, Thomas Doughty, eram vistos como "marinheiros de água doce", cortesãos de hábitos eruditos desenvolvidos desde o nascimento.

A disputa emblemática entre esses homens ilustra as tensões que se fizeram presentes no seio de um novo quadro institucional e profissional, ao mesmo tempo militar e náutico, resultante de um processo que durou mais de um século, iniciado com as exigências da 
expansão marítima e do aumento das rivalidades nos mares. O novo establishment especializado, a Marinha, incluía padrão de comportamento e regras que visavam o autodomínio. Ainda, conforme Elias, a emergência desta modalidade de instituição naval encontrava-se submetida a um quadro organizacional autoritário, fruto de um longo processo de tentativa e erro, sendo resultado da interação entre técnicas e exigências sociais (ELIAS, 2001).

Até o século XIX, buscava-se a proficiência de forma prática e aleatória no convés do navio, requerendo-se dos aspirantes exames de navegação e marinhagem e permitindo que generais e nobres pudessem comandar esses navios sem experiência prévia, dando-se primazia aos vínculos aristocráticos. Com o progresso tecnológico alcançado no século XIX, exigia-se uma perícia cada vez maior para tripular embarcações mais sofisticadas, influenciando a própria identidade dos oficiais e dos marinheiros.

Ademais, por meio das concepções profissionais que se desenvolveram com o iluminismo militar, houve completa definição do seu perfil: "A substituição da vela pelo vapor iria libertar o marinheiro das preocupações com navegabilidade, permitindo o desenvolvimento de princípios gerais e abstratos de Estratégia Naval, como Jomini e Clausewitz já haviam formulado para operações terrestres" (HUNTINGTON, 1997: 275).

No século XIX, a doutrina militar de Jomini que inaugurava a gestão da guerra pela vertente científica, contemplando os campos da Estratégia, Grande Tática e Logística, determinou o fim do amadorismo de governantes e nobres no campo bélico e a demarcação de uma fronteira clara entre militares e civis. Assim, suas contribuições transformaram-se na escola mais influente da teoria militar e a raiz das forças armadas nacionais profissionais, fazendo proliferar as Escolas militares por toda a Europa. Para ele, "o contexto da guerra era marcado por uma grande continuidade de valores tradicionais, em que um grande líder inspirava os valores locais de um povo e os fazia transcender sua rotina bélica num grande pulso heroico" (BRASIL, 2007: 3-3).

Surgia, então, um profissional da terra e do mar que passou a lutar por uma pátria, alterando a anterior missão do cavaleiro medieval que lutava para servir a Deus. Observa-se que a formação da categoria profissional de militar em vigência foi atravessada por circunstâncias presentes em um dado momento histórico. Os preceitos e valores militares foram culturalmente construídos para servirem a objetivo relacionado a questões de poder, transformando o sujeito em uma peça de sua engrenagem. Ao invés de naturalizar essa profissão, cabe compreender que uma ocupação é histórica não em função de sua idade, mas porque sua atividade principal há muito tempo tem nome, licença, mandato e lugar reconhecido num certo cenário (HUGHES, 1971).

Nesse sentido, a Marinha reedita, cotidianamente, estratégias para manter sua identidade e continuidade institucional, exaltando ilustres patronos e heróis, cultuando 
episódios legendários e históricos, nas solenidades, nas formaturas e nas tradições. $\mathrm{O}$ próprio conceito que a profissão naval tem de si afeta o imaginário de seus integrantes, modelando suas identidades. Nutridos por essas visões, retroalimentam essa equação, corroborando a própria existência da ocupação militar naval, retroalimentando esse sistema.

A existência de determinados grupos, tais como as Forças Armadas que, a despeito de terem uma evolução temporal observável, "concebem-se como eternos e imutáveis, provavelmente porque daí deriva parte de sua legitimidade e porque tendem a se conceberem por meio de certos princípios organizacionais como a hierarquia, a descendência, a honra, a fé e o sangue" (DA MATTA, 1997: 24).

Compreendendo-se que a MB como organização administrativa e operativa era distinta daquele poder naval que dominava os mares, seus integrantes também passaram por mudanças, acompanhando as transformações que se operaram no seio institucional e no contexto político e econômico brasileiro. Com o modelo o do soldado-cidadão, disciplinado e obediente, diversas estratégias foram construídas no passado e continuam a ser aplicadas e reproduzidas no cotidiano laborativo de modo a assegurar a introjeção da identidade militar na mentalidade do sujeito. Decidiu-se nomear de enfardamento o processo de assimilação dos valores e preceitos militares ao ponto de conformarem uma "mentalidade" ou um "espírito", capaz de fazer do indivíduo um membro do corpo militar e servidor da pátria.

A trajetória do enfardamento se desenrola de duas formas: por um lado, ela ocorreu ao longo da história, desde o audaz marujo que enfrentava os mares desconhecidos em busca de tesouros que se converteu em um integrante fardado da pirâmide hierárquica, especializado no manuseio de equipamentos de navegação sofisticados. Por outro lado, o enfardamento se atualiza diariamente no seio institucional por meio de diversas estratégias, como serão expostas a seguir.

Ainda como candidato, o jovem é submetido aos critérios da seleção, de acordo com um perfil profissional e pessoal previamente estabelecido, incluindo provas teóricas, exames de saúde, testagem psicológica e de aptidão física, correspondendo à implantação de uma pedagogia da liminaridade (TURNER, 1974). Trata-se de período liminar no qual, indivíduos iguais, em comunhão uns com os outros, que compõem um grupo não estruturado (ou rudimentarmente estruturado) e relativamente indiferenciado, são submetidos, em conjunto, a uma autoridade. Após a seleção, os calouros militares, como sujeitos liminares, não possuem status, propriedades, insígnias, marcas identificatórias que os diferenciem de seus colegas novatos.

Findo esse período "iniciático", cumprido o rito de passagem, eles são investidos dos símbolos que assinalarão aos demais suas posições na estrutura social. A liminaridade, portanto, corresponde ao tempo de passagem de um estado para outro, sendo, geralmente 
comparado à morte. Desde o recrutamento, espera-se selecionar um candidato que se encaixe nos critérios estipulados. Adiante, a aplicação de medidas padronizadoras escamoteia diferenças. Para tal, faz-se necessária a sua morte civil, ou melhor, o sujeito deve cumprir processos institucionais de perda e de mortificação (GOFFMAN, 1961/1992). Para facilitar a incorporação de uma identidade militar, o neófito deverá se enquadrar, submetendo-se a exames clínicos, corte de cabelos, uso de uniformes e a escolha de um nome de guerra. Trata-se de uma "formatação" que precisará ser mantida ao longo da carreira, assegurando o nivelamento e o controle, onde, qualquer conduta que fuja à regra, poderá ser considerada como desviante.

Nas escolas de formação objetiva-se alcançar a chamada "vitória cultural" sobre o aprendiz durante o período liminar (CASTRO, 2004). O curso na Academia militar seria uma espécie de ritual de passagem que permitiria colocar em curso o processo de construção da identidade social do militar e o espírito militar (CASTRO, 1993). Nessa fase, haveria um intenso processo de socialização profissional, determinando a construção de fronteiras simbólicas entre militares e civis, o que contribuiria para o desenvolvimento do espírito militar. Sobretudo, a identidade militar seria delineada pelas distinções entre o "aqui dentro" e o "lá fora", não apenas por meio de elementos palpáveis como o uso do uniforme.

Atributos morais associados à "honestidade", "retidão de caráter" e o "espírito de renúncia", vinculados ao respeito à ordem, hierarquia e disciplina, reforçariam essas fronteiras. Embasado no modelo de Simmel, esses "espíritos" ou "identidades" seriam fiç̧ões inventadas de modo a sintetizarem elementos que, de outra forma, estariam difusos, fruto de interações entre indivíduos que criam a sociedade, no decorrer de um processo em permanente estado de constituição. "A ideia é que o 'espírito militar' não é uma constante, mas sim um sistema segmentário em relação ao qual o valor de cada um dos espíritos se define" (CASTRO, 2004: 102), sendo que uma das características mais importantes dos sistemas segmentários seria sua relatividade estrutural.

Daí, Castro concorda com Duarte quanto à importância da contrastividade (oposição) e da não-substancialidade de toda a identidade (incluindo a militar), conferindo ênfase à sua natureza simbólica (DUARTE, 1986 apud CASTRO, 2004).

Os espíritos ou identidades militares não são, portanto, molduras fixas às quais os indivíduos conformam-se, mas um equilíbrio dinâmico entre tendências opostas, embora complementares, para a fissão e a fusão; e uma certa tensão na definição dos espíritos é inerente ao sistema (CASTRO, 2004: 104).

Entretanto, a noção de "espírito" está comprometida com o estabelecimento de ligações simbólicas entre fenômenos simultâneos ou sucessivos de uma determinada época, 
constituindo uma comunidade de sentido, assentada em um jogo de semelhança e de espelho. Reforçando a crença na continuidade de modo a diluir diferenças e apagar rupturas e transformações, emergiria “(...) com princípio de unidade e de explicação, a soberania de uma consciência coletiva”. (FOUCAULT, 1969/2012: 26).

Ao invés de sustentar a concepção iluminista de uma "identidade militar" referida a uma essência que se mantem estável e intocada, no mundo contemporâneo as identidades seriam fragmentadas e constantemente redefinidas. Portanto, ao invés de uma "identidade militar" haveria uma "identificação militar" (GIULIANI, 2006):

\footnotetext{
Os conceitos de classe, gênero, etnia, raça, civilização, grau de industrialização, tecnologia, entre outros, que serviam para solidificar sujeitos integrados, estão perdendo sentido. Esses aspectos nos fazem pensar que falar em identidade se torna uma questão altamente problemática, pois sua definição está em crise. Qualquer concepção essencialista ou fixa de identidade, como a construída no período iluminista, que supunha definir o próprio núcleo ou essência do nosso ser e fundamentar existência dos sujeitos humanos, está desacreditada (GAUER, 2004: 251).
}

Percebe-se a existência de um caráter provisório e circunstancial da "identificação militar", aspecto que pôde ser constatado ao longo desse texto por meio dos diversos tipos de indivíduos que ingressaram nas fileiras e nas embarcações (mercenários, vagabundos, libertos, negros, pardos, solteiros, até os filhos das elites para serem oficiais da Marinha), circunstâncias e objetivos. Ademais, essa relatividade é exemplificada pelo novo papel social requerido do militar brasileiro em fins do século XIX e inicio do XX que substitui a antiga "escória" dos séculos XVIII e XIX (McBETH, 1977; COSTA, 1995; MENDES, 1998; NASCIMENTO, 2001), recrutada à força em esquinas, becos e tavernas para ajudar a manter a cidade limpa e organizada. Em conformidade com os emergentes padrões materiais e comportamentais que determinaram o homo urbanus, fruto do processo civilizatório, esperava-se construir as bases das Forças Armadas brasileiras com o suporte de um contingente supostamente hígido e produtivo, segundo o ethos do trabalho, à luz do sistema de valores e da redefinição política e identitária estabelecidos com o sistema republicano no Brasil.

Em suma, os princípios que embasam as organizações militares são histórica, econômica e culturalmente produzidos. Assim sendo, determinadas concepções como a de "dar a vida por uma causa" ou de "morrer pela Pátria" são datadas, mas não necessariamente têm sido atualizadas ou revistas. De fato, esses são pontos de vista que prevaleceram na França revolucionária, quando se pregava a ideia de "dar a vida pela revolução", fazendo pleno sentido naquela paisagem. 
Porém, na atualidade, as narrativas sobre os episódios históricos navais continuam a reforçar a valentia de heróis nacionais, exercendo um poder mítico capaz de alavancar a motivação para a batalha, servir de fonte de inspiração e consolidar o "espírito de corpo" e a "identidade militar". Em contrapartida, elas podem acabar se tornando a versão oficial dos fatos, “(...) tomando a fábula pela realidade, deslocando-a de sua função original e edificando-a em História" (BRASIL, 2007: 1-12). Nesse sentido, acabam por induzir uma falsa realidade, despreparando o militar para a realidade amarga dos combates.

\section{Considerações finais}

Constatou-se a existência de uma manobra interessada em assegurar a continuidade das noções de "tradição", "pátria", "nação", "patriotismo", "cidadão", "soldado", "guerra", fazendo crer que são permanentes. No entanto, percebe-se que elas não têm uma estrutura conceitual rigorosa, mas uma função bastante precisa. De fato, esses grupamentos são percebidos pelo senso comum, como se fossem universais e naturais (FOUCAULT, 1969/2012). Porém, acredita-se que, por detrás de uma sucessão de narrativas tradicionais, atualizadas no cotidiano, haveria uma densa camada de acontecimentos que precisam ser esmiuçados.

Ao invés de se empreender uma reflexão centrada na identificação de suas semelhanças e continuidades para encontrar aquilo o que se supõe ser constante e comum, desejou-se pôr em relevo suas interrupções e descontinuidades, de modo a desconstruir noções que fortalecem o imobilismo e a mera repetição, reforçando a permanência de certos mitos que podem propiciar a discriminação e a repressão, a serviço de um "alguém" (existem muitos "alguéns"). A naturalização dessas noções viabiliza a pasteurização dos indivíduos, como se não houvesse consensos coabitando com as contradições.

É sempre necessário colocar em exame essas sínteses acabadas, que estabelecem agrupamentos que tendem a ser assimilados sem um trabalho de reflexão. Assim concebidas, reforçam laços que são reconhecidos como válidos desde sua gênese (mítica). Em seu bojo, tais noções pressupõem seu caráter evolutivo, guardam uma valoração associada à visão de "progresso" ao longo de uma suposta trajetória percorrida de modo linear e ascendente, alojando-se e cristalizando-se no discurso e nas práticas da vida em sociedade. Com efeito, a partir delas, um feixe de relações se dissemina em múltiplas direções, arraigando-se e tornando-as "verdadeiras" por mecanismos de reprodução e de multiplicação.

Desse modo, elas camuflam o seu caráter variável e relativo. Os valores e preceitos militares concebidos como sínteses assumem um caráter dogmático, justificando-se por si 
mesmos sem serem problematizados. De fato, eles são efeitos de uma construção cujas regras e objetivos precisam ser conhecidos. Todavia, colocá-los em suspenso permite indagar sobre sua legitimidade, libertando-se do automatismo que procura afirmar sem dar espaço à contestação.

Mais do que naturalizá-los, foi preciso identificar os acontecimentos discursivos que serviram de pano de fundo para seu desenho: sobretudo as questões de poder. A análise do campo discursivo contribuiu para rever essas noções, identificando um elo estreito com os enunciados que são hegemônicos em um dado recorte social, histórico e cultural, mas, ao mesmo tempo, excluindo outras possibilidades.

\section{Referências Bibliográficas}

ARIAS NETO, José Miguel. Marinha do Brasil como imagem da nação: o pensamento de monarquistas e republicanos sobre a Marinha do Brasil em fins do século XIX, Revista Marítima Brasileira, v. 121, p. 105-115, 2001.

ARIAS NETO, José Miguel. A Formação do Estado Nacional e as Forças Armadas. 'Usos do Passado' - XII Encontro Regional de História ANPUH-RJ 2006 $<$ http://www.rj.anpuh.org/resources/rj/Anais/2006/conferencias/Jose\%20Miguel\%20Arias\% 20Neto.pdf $>$

BEATTIE, Peter M. Ser homem pobre, livre e honrado: a sodomia e os praças nas Forças Armadas brasileiras (1860-1930). In: CASTRO, Celso; IZECKSOHN, Vitor; KRAAY, Hendrik (Orgs.). Nova história militar brasileira. Rio de Janeiro: FGV, 2004. p. 269-299.

BRASIL. Constituição Política do Império do Brazil de 1824. Coleção de Leis do Império do Brasil de 1824. Disponível em:

<http://www.planalto.gov.br/ccivil_03/constituicao/constitui\%C3\%A7ao24.htm> Acesso em: 09 mai. 2013.

Escola de Guerra Naval. EGN-304B: Guia para estudos de estratégia. Rio de Janeiro: Escola de Guerra Naval, 2007.

CAMINHA, Adolfo. Bom crioulo. São Paulo: Martin Claret, 2007 [1895]. 157p.

CARVALHO, Zenithilde Magno de. A Marinha no Brasil colonial. Rio de Janeiro: Livraria Leite, 1928. 790p. 
CARVALHO, José Murilo de. Brasil: nações imaginadas. Antropolítica: Revista Contemporânea de Antropologia e Ciência Política, v. 1, n. 1, p. 7-36, 1995.

. Os negros armados pelos brancos e suas independências no nordeste, 18171848, In: JANCSÓ, I. (Org.). Independência: história e historiografia. São Paulo: Hucitec/FAPESP, 2005. p. 881-914.

CASTRO, Celso. A origem social dos militares: novos dados para uma antiga discussão. Novos Estudos CEBRAP. (37), p. 225-231, 1993.

O espírito militar: um antropólogo na caserna. Rio de Janeiro: Zahar, 2004. $182 \mathrm{p}$.

CENTENO, Miguel Angel. Blood and debt: war and the nation-state in Latin America. University Park, PA: Pennsylvania State University Press, 2002. 344p.

COSTA, Samuel Guimarães da. Formação democrática do Exército brasileiro; pequena tentativa de interpretação social. Rio de Janeiro: Biblioteca do Exército, 1957.

COSTA, Fernando Dores. Os problemas do recrutamento militar no final do século XVIII e as questões da construção do estado e da nação, Análise Social, v. 30, n. 130, p. 121-155, 1995.

COTTA, Francis Albert. $O$ "sistema militar corporativo" na América Portuguesa. Trabalho apresentado no Congresso Internacional "O espaço atlântico do antigo regime: poderes e sociedades”, na Universidade Nova de Lisboa, Lisboa, Portugal, 2005.

DA MATTA, Roberto. Carnavais, malandros e heróis: para uma sociologia do dilema brasileiro. 6. ed. Rio de Janeiro: Rocco, 1997. 366p.

ELIAS, Norbert. $A$ sociedade de corte. Lisboa: Editorial Estampa, 1987. 316p.

. Os alemães: a luta pelo poder e a evolução do habitus nos séculos XIX e XX. Rio de Janeiro: Zahar, 1997. 432p.

. Estudos sobre a gênese da profissão naval: cavalheiros e tarpaulins. Mana: Estudos de Antropologia Social, v. 7, n. 1, p. 89-116, 2001.

Processos de formação de Estados e construção de nações. In: NEIBURG, Frederico; WAIZBORT, Leopoldo (Orgs.). Escritos \& ensaios 1: Estado, processo, opinião pública. Rio de Janeiro: Zahar, 2006. p. 153-165.

FOUCAULT, Michel. $A$ arqueologia do saber. Tradução Luiz Felipe Baeta Neves. $8^{\mathrm{a}}$ ed. Rio de Janeiro: Forense Universitária, 2012 [1969]. 
. Vigiar e punir. nascimento da prisão. 34. ed. Petrópolis, RJ: Vozes, 2007 [1975]. 290p.

. Microfísica do poder. Rio de Janeiro: Graal, 1979. 295p.

GAUER, Ruth. Interrogando o limite entre historicidade e identidade. In: GAUER, Ruth (Org.). A qualidade do tempo para além das aparências históricas. Rio de Janeiro: Lumen Juris, 2004.

GILBERT, Felix. Maquiavel: o renascimento da arte da guerra. In: PARET, Peter. (Org.). Construtores da estratégia moderna: de Maquiavel à era nuclear. Rio de Janeiro: Biblioteca do Exército, 2001. p. 27-53.

GIULIANI, Ricardo Henrique Alves. Processo penal militar: uma análise do ritual judiciário, disciplina e hierarquia. Dissertação (Mestrado em Ciências Criminais) Faculdade de Direito, PUCRS. Porto Alegre. 2006a; _._._._. Ritual e Processo Penal Militar: hierarquia e disciplina na (dis)função de julgar do Juiz Militar <http://www.dpu.gov.br/pdf/artigos/Artigo_Juiz_Militar.pdf> Acesso em 09 maio 2013. 2006.

GOFFMAN, Erving. Manicômios, prisões e conventos. São Paulo: Perspectiva, 1992 [1961]. 320 .

HUGHES, Everett C. The sociological eye: selected papers. Chicago \& New York: AldineAtherton, 1971. 584p.

HUNTINGTON, Samuel P. O soldado e o estado: teoria e política das relações entre civis e militares. Rio de Janeiro: Bibliex, 1997. 547p.

IZECKSOHN, Vitor. Recrutamento militar no Rio de Janeiro durante a Guerra do Paraguai. In: CASTRO, Celso; IZECKSOHN, Vitor; KRAAY, Hendrik (Orgs.). Nova história militar brasileira. Rio de Janeiro: FGV, 2004. p. 179-207.

KRAAY, Hendrik. "O abrigo da farda": o Exército brasileiro e os escravos fugidos, 1800-1888. Afro-Asia. Salvador, v. 17, p. 29-56, 1996.

Em outra coisa não falavam os pardos, cabras, e crioulos: o "recrutamento" de escravos na guerra da independência na Bahia, Revista Brasileira de História, v. 22, n. 43, p. 109-126, 2002. 
Arming slaves in Brazil from the seventeenth century to the nineteenth century. In: BROWN, Christopher Leslie; MORGAN, Philip D. (Eds). Arming slaves: from classical times to the modern age. New Haven, CT: Yale University Press, 2006. p. 146-179.

LUZ, Madel Therezinha. Medicina e ordem política brasileira: políticas e instituições de saúde (1850-1930). Rio de Janeiro: Graal, 1982. 218p.

. Natural, racional, social: razão médica e racionalidade científica moderna. Rio de Janeiro: Campus, 1988. 151p.

MARTINS, Helio Leoncio. João Cândido e a Revolta de 1910. Navigator - Subsídios para a História Marítima do Brasil. Rio de Janeiro: Serviço de Documentação da Marinha, v. 1, n. 1, p. 76-84. 2005.

McBETH, Michael G. The Brazilian recruit during the First Empire: slave or soldier? In: ALDEN, Dauril; DEAN, Warren (Eds.). Essays concerning the socioeconomic history of Brazil and Portuguese India. Gainesville, FL: The University Presses of Florida, 1977. p. 71-86.

McCANN, Frank D. The nation in arms: obligatory military service during the Old Republic. In: ALDEN, Dauril; DEAN, Warren (Eds.). Essays concerning the socioeconomic history of Brazil and Portuguese India. Gainesville, FL: University Presses of Florida, 1977. p. 211-243.

MENDES, Fábio Faria. A economia moral do recrutamento militar no Império brasileiro. Revista Brasileira de Ciências Sociais, São Paulo, v. 13, n. 38, Oct. 1998. Available from $<$ http://www.scielo.br/scielo.php?script=sci_arttext\&pid=S0102-

69091998000300005\&lng=en\&nrm=iso>. access on 22 May 2013. http://dx.doi.org/10.1590/S0102-69091998000300005.

Encargos, privilégios e direitos: o recrutamento militar no Brasil nos séculos XVIII e XIX. In: CASTRO, Celso; IZECKSOHN, Vitor; KRAAY, Hendrik (Orgs.). Nova história militar brasileira. Rio de Janeiro: FGV, 2004. p. 111-137.

MONTEIRO, Tobias. A elaboração da independência. São Paulo: EDUSP; Belo Horizonte: Itatiaia, 1981.

NASCIMENTO, Álvaro Pereira do. A ressaca da marujada: recrutamento e disciplina na Armada Imperial, 1880-1919. Rio de Janeiro: Arquivo Nacional, 2001. 165p

PALMER, R. R. Frederico, o grande, Guibert, Bülow: da guerra dinástica à guerra nacional. In: PARET, P. (Org.). Construtores da estratégia moderna: de Maquiavel à era nuclear. Tradução de Joubert de Oliveira Brízida. v.1. Rio de Janeiro: Biblioteca do Exército Editora, 2001. p. 2753. 
RELATÓRIO Apresentado a Assembléia Geral Legislativa da Quarta Sessão da Décima Segunda Legislatura pelo Ministro e Secretário de Estado dos Negócios da Marinha Francisco de Paula da Silveira Lobo. Rio de Janeiro: Typographia Perseverança, 1866.

RODRIGUES, Flávio Luís. L. Vozes do mar. o movimento dos marinheiros e o golpe de 64 . São Paulo: Cortez, 2004. 208p.

SCHULZ, John. O Exército na política: origens da intervenção militar, 1850-1894. São Paulo: Editora da Universidade de São Paulo, 1994. 224p.

SODRÉ, Nelson Werneck. História militar do Brasil. Rio de Janeiro: Civilização Brasileira, 1965. 576p.

TILLY, Charles. How war made states and vice-versa. New York: New School for Social Research, 1987.

_. States and nationalism in Europe, 1442-1492. Theory and Society, v. 1, n. 23, 1994.

. Capital, coerção e estados nacionais. São Paulo, SP: EDUSP, 1996. 360p.

TURNER, Victor W. O processo ritual: estrutura e antiestrutura. Petrópolis, RJ: Vozes, 1974. 245 .

Texto recebido em 27 de fevereiro de 2014 e aprovado em 3 de maio de 2014 